\title{
ARAŞTIRMA / RESEARCH \\ Periodontal cerrahi öncesi dental anksiyete düzeyi ve progresif gevşeme egzersizlerinin vital bulgular üzerine etkisi
}

\author{
Effect of dental anxiety level and progressive relaxation exercises on vital signs before \\ periodontal surgery
}

Gülhan Kocaman1D

${ }^{1}$ Karabük Üniversitesi, Diş Hekimliği Fakültesi, Periodontoloji Anabilim Dalı, Karabük, Turkey

Cukurova Medical Journal 2019;44Suppl 1):352-357.

\begin{abstract}
Purpose: The aim of this study was to evaluate the dental anxiety levels of patients before periodontal surgery and to evaluate the effects of preoperative progressive relaxation exercises on vital signs and mouth opening.

Materials and Methods: A total of 35 randomly selected patients who were scheduled for periodontal surgery were included in the cross-sectional study. Demographic data and a questionnaire including Corah Dental Anxiety Scale were applied before the surgery. Systolic and diastolic blood pressure, pulse and respiration including vital signs and mouth opening were measured. Then 30 minutes of relaxation exercise was performed. She was asked to take the position where she felt most comfortable and close her eyes. The environment is kept quiet. Thirty minutes of relaxation exercises were listened with a video headset and allowed to do the exercises. Vital signs and mouth opening were measured again after relaxation exercise.

Results: $71.4 \%$ of the patients stated that dental treatment was not fearful, but the rate of dental anxiety before periodontal surgery was found to be $57.1 \%$. Systolic blood pressure and mouth opening were significantly affected after relaxation exercise but no statistically significant change was observed in diastolic blood pressure, pulse and respiration measurements

Conclusion: Progressive relaxation exercise applied before periodontal surgery has a myorelaxant activity in increasing the mouth opening and it is a cheap, painless, non-adverse non-pharmacological anxiolytic in reducing systolic blood pressure.
\end{abstract}

Keywords: Prograsive relaxation exercise, periodontal surgery, dental anxiety, vital signs.
Öz

Amaç: Periodontal cerrahi öncesi hastaların dental anksiyete düzeylerini değerlendirmek ve ameliyat öncesi yapılan progresif gevşeme egzersizlerinin vital bulgular ve ağız açıklığ1 üzerine etkisini incelemek amaciyla planlanmıștır.

Gereç ve Yöntem: Kesitsel tipte planlanan çalışmaya periodontal cerrahi tedavi için randevu verilen randomize 35 hasta dahil edildi. Cerrahi uygulama öncesi onamları alınarak demografik bilgiler ve Corah Dental Anksiyete Skalası içeren anket uyguland. Tansiyon, nabız ve solunumu içeren vital bulguları ve ağız açıklığı ölçümü yapıldı. Gevşeme egzersizi uygulaması öncesi ortamın sessiz bir ortamda hastaya oturur durumda, kendini en rahat hissettiği pozisyonu alması, gözlerini kapatması istendi. Otuz dk'llk gevşeme egzersizlerini anlatan video kulaklıkla dinlettirildi ve egzersizleri yapması sağlandı. Gevşeme egzersizi sonrası vital bulgular ve ağı açıklığı ölçümleri tekrarlandı.

Bulgular: Hastaların 71.4\%'ü diş tedavilerinin korku verici olmadığını ifade etmelerine rağmen periodontal cerrahi öncesi dental anksiyete oran1 $57.1 \%$ olduğu tespit edilmiştir. Gevşeme egzersizi uygulaması sonrası sistolik kan basıncı ve ağız açıklı̆̆ı anlamlı olarak etkilendiği ancak diyastolik kan basıncı, nabız ve solunum ölçümlerinin ise istatistiksel olarak anlamlı bir değişiklik olmadığı saptandı. Sonuç: Periodontal cerrahi öncesi uygulanan progresif gevșeme egzersizinin ağız açıklığını arttırmada myorelaksan etkinliği olduğu ve sistolik tansiyonun düşürülmesinde ucuz, ağrısız, yan etkisiz non-farmakolojik anksiyolitik olduğu belirlenmiştir.

Anahtar kelimeler: Prograsive gevșeme egzersizi, periodontal cerrahi, dental anksiyete, vital bulgu.

Yazışma Adresi/Address for Correspondence: Dr. Gülhan Kocaman, Karabük Üniversitesi, Diş Hekimliği Fakültesi, Periodontoloji Anabilim Dalı, Karabük, Turkey E-mail: dentist25@hotmail.com

Geliş tarihi/Received: 30.04.2019 Kabul tarihi/Accepted: 03.08.2019 Çevrimiçi yayın/Published online: 27.09.2019 


\section{GİRİ̧̧}

Periodontal cerrahi uygulamalar genellikle lokal anestezi altında yapılan cerrahi ișlemlerdir. Hastaların birçoğu yapılan bu cerrahi müdahaleler ile ilgili korku ve anksiyete sorunu yaşamaktadır. Anskiyete, psikodinamik açıdan id, ego ve süper ego arasındaki çatışmanın bir göstergesi olarak ortaya çıkan ve psikolojik gerilimle karakterize nedeni bilinmeyen huzursuzluk ve endișe halidir ${ }^{1,2}$. Dental anksiyete ise diş hekimliği uygulamalarına bağlı olarak gelişir ve genel anksiyeteden daha spesifiktir. Hastanin dental tedavisi esnasında maruz kaldığ1 spesifik streslerin hastada oluşturduğu tepki olarak tanımlanmaktadır ${ }^{3-5}$. Diş hekimliğindeki modern teknolojik uygulamalara ve gelişmelere rağmen dental cerrahiye ve dental tedavilere ait anksiyete ve tedavi sırasındaki ağrı korkusu devam etmektedir ${ }^{6}$.

Hastaların lokal anestezi yapılması ve bilinci açık cerrahi müdahale yapılacağı düşüncesi dental anksiyeteyi tetiklemektedir.

Dental korku ve anksiyete hastalarda pek çok fizyolojik ve davranısssal yanıtlara neden olmaktadır ${ }^{7}$. Hastaların muayenehanede gösterdikleri ilk ve en önemli anksiyete belirtisi nefes almada düzensizliktir ${ }^{8}$.

Çenelerde kitlenme, dişlerin sıkılması, kaslarda gerginlik ve ekstremitelerde sertlik, soğuk terleme ve titreme, baş dönmesi, tansiyon arteriyel ve nabızdaki değişiklikler, senkop, hiperestezi ve parasteziler gibi belirtiler ortaya çıkabilirr ${ }^{1-8}$. Dental anksiyeteye sahip bireylerde diş hekimi randevularını erteleme hatta diş hekiminden tamamen kaçınma durumları görülmektedir. Ansiyetenin diş hekimliği ve dental cerrahi işlemlerinin gerçekleştirilmesi için engel oluşturabileceği ve ağı hastalıkları insidansını arttırabileceği vurgulanmıştır ${ }^{9-11}$. Cerrahi öncesi anksiyete düzeyi yüksek olan hastalarda postoperatif dönemde daha fazla komplikasyon geliştiği ve iyileşmenin geciktiği bildirilmiştir ${ }^{2}$. Bu nedenle dental cerrahi öncesi anksiyetenin giderilmesinde farmakolojik tedavilerin yanı sira nonfarmakolojik psikosedatif teknikler de kullanılmaktadır ${ }^{12-15}$.

Progresif gevşeme egzersizleri non farmakolojik yöntemlerden bir tanesidir. Gevşeme egzersizlerinin temel dayanak noktası anksiyete ile ilişkili kas gerginliğidir. Kaslarda gevşetilme sağlanırsa, anksiyete de bağlantılı olarak azalacaktır ${ }^{16}$. Gevşeme teknikleri ile oksijen tüketiminin kontrolü, kas tonüsü, kalp ve solunum hızının azalması, kan basıncının düşmesi sağlanmaya çalışılır, fiziksel ve mental durum iyileştirilirr ${ }^{17}$.

$\mathrm{Bu}$ çalışma, periodontal cerrahi uygulamaları için gelen hastaların anksiyete düzeylerinin belirlenmesi ve ameliyat öncesi yapılan gevşeme egzersizlerinin ve vital bulgular ve ağı açılklı̆g üzerine etkisini incelemek amacıyla planlanmıştır.

\section{GEREÇ VE YÖNTEM}

Bu çalışma Girişimsel Olmayan Klinik Araştırmalar Etik Kurulu'ndan 01/11/2017 tarih ve 10/7 numaralı etik kurul izni alınarak çalışmaya başland. Kesitsel tipte planlanan çalışmaya, peridontoloji kliniğine başvuran, başlangıç tedavileri yapılmış periodontal cerrahi ihtiyac1 olduğu saptanan, örneklem kapsamında araştırma kriterlerini karşılayan 35 hasta dahil edildi. Gönüllülük ilkesine özen gösterilerek çalışma grubunu oluşturan hastalara çalışmanın amaç ve yararları, çalışmadaki rolleri ile ilgili açıklama yapılarak bilgilendirilmiş onamları alınarak veri toplama formunu doldurmaları istendi.

\section{Veri toplama ve ölçekler}

Veri toplama formu üç kısımdan oluşmaktadır. Birinci kısım hastanın sosyodemografik bilgileri, ikinci kısım Corah'ın geliştirmiş olduğu Dental Anksiyete Skalası, üçüncü kısımda ise hastaların yaşam bulgularını ve ölçümleri kaydetmek için hasta izlem formu kullanildı.

\section{Corah Dental Anksiyete Skalası}

Corah Dental Anksiyete Skalası1 ${ }^{18}$ (DAS) diş hekimliğinde anksiyetenin belirlenmesinde en sik kullanılan ölçeklerin biridir. Seydaoğlu ve $\operatorname{ark}^{19}$. tarafindan Türkçeye uyarlanan skala, dental girişimlerde kişilerin kendilerini ne kadar endişeli ve kaygılı hissettiklerini ölçmeye yönelik 4 maddeden oluşan, beşli likert tipi bir ölçektir. Ölçekten alınabilecek en yüksek puan 20 , en düşük puan ise 4'tür. Puanın yüksek olması kişinin yüksek anksiyeteye sahip olduğunu göstermektedir. Dört soruya verilen puanların toplanması ile elde edilen toplam dental anksiyete puanı, 4-7 puan= anksiyetesi olmayanlar, 8-20 puan=anksiyetesi olanlar şeklinde değerlendirildi.

Periodontal cerrahi işlemi öncesi demografik bilgiler ve anksiyete skalası alınd,, sistolik ve diastolik kan basıncı, kalp atım hızını ölçebilen standart tek bir monitörize tansiyon aleti yardımı ile ölçüldü. 
Solunum hızı, 1 dakikalık diyafram hareketi sayısı ile ve ağız açılklı̆ı ise bir kumpas yardımıyla tek standart bir araştırmacı tarafından ölçüldü.

Gevşeme egzersizleri öncesi hastalara uygulama hakkında bilgi verildi. Hastaya oturur durumda kendini en rahat hissettiği pozisyonu alması, gözlerini kapatması istendi ve ortamın sessiz olması sağlandi. Türk Psikoloji Derneği tarafindan onaylanan 30 dakikalık gevşeme egzersizlerini anlatan video kulaklıkla dinlettirildi ve egzersizleri yapması sağlandı. Gevşeme egzersizi sonrası vital bulgular ve ağız açıklığ1 tekrar kaydedildi.

\section{İstatistiksel analiz}

Elde edilen verilerin istatistiksel değerlendirmesinde gruplar arasında normal dağılan sürekli ölçümlü değişkenler yönünden istatistiksel anlamlı bir farkın olup olmadığı Student's t testi, normal dağılmayan sürekli ölçümlü değişkenler Mann Whitney U testiyle değerlendirildi. Grup içi tekrarlayan ölçümler için tekrarlı ölçümlü varyans analizi kullanıldı, bu analizin anlamlı bulunduğu durumlarda Bonferroni düzeltmeli çoklu karşılaştırma testi yapıldı. Grup içi yineleyen OAA/SS ölçümleri arasında anlamlı fark olup olmadığ1 Friedman testi ile değerlendirilerek, anlamlı bulunduğu durumlarda Bonferroni düzeltmeli Wilcoxon işaret testi yapıldı. Kategorik değişkenler Pearson ki-kare ve Fisher'in tam sonuçlu olasılık testi ile değerlendirildi. Tüm değerlendirmelerde $\mathrm{p}<0,05$ olarak kabul edildi.

\section{BULGULAR}

Araştırmaya katılan hastaların yaş, cinsiyet, eğitim durumu, gelir durumu gibi sosyo-demografik özellikleri Tablo 1'de verilmiştir. Çalışmada yer alan 35 olgunun 65.7\%'si kadın, 34.3\%'ü erkek olup yaş ortalamas1 42,57'dir. Katılımciların 48.6\%'s1 ilköğretim ve alt1, 25,7\%'si lise ve $25.7 \%$ 'si ise üniversite ve üzeri eğitime sahiptir. 42.9\%'u düşük, $57.1 \%$ 'i orta ve yüksek gelir durumuna sahiptir. Araştırmaya katılan hastalardan \%20'si sistemik hastalığa sahipken, 11.4\%'ünde sürekli ilaç kullanımı saptanmıştır. Daha önce lokal anestezi altında işlem geçiren hasta oranı $22.9 \%$ diş ile ilgili cerrahi işlem geçiren hasta oranı 17.1\%'dir. Katılımcıların 28.6\%'s1 diş tedavisini korku verici bulmaktadır.

Tablo 1. Hastaların sosyodemografik özellikleri

\begin{tabular}{|c|c|c|c|}
\hline \multicolumn{4}{|l|}{ Değişken } \\
\hline \multirow[t]{2}{*}{ Yaş } & \multicolumn{3}{|c|}{$42.57 \pm 10.66(\mathrm{Min}=23, \mathrm{Max}=65)$} \\
\hline & & $\mathrm{n}$ & $\%$ \\
\hline \multirow[t]{2}{*}{ Cinsiyet } & Kadin & 23 & 65.7 \\
\hline & Erkek & 12 & 44.3 \\
\hline \multirow[t]{3}{*}{ Eğitim düzeyi } & İlköğretim va alt1 & 17 & 48.6 \\
\hline & Lise & 9 & 25,7 \\
\hline & Üniversite ve üzeri & 9 & 25.7 \\
\hline \multirow[t]{2}{*}{ Gelir durumu } & Düşük & 15 & 42.9 \\
\hline & Orta ve yüksek & 20 & 57.1 \\
\hline \multirow[t]{2}{*}{ Yaşanılan yer } & Köy-İlçe & 11 & 31.4 \\
\hline & İl & 24 & 68.6 \\
\hline \multirow[t]{2}{*}{ Sistemik hastalık varlığ1 } & Yok & 28 & 80.0 \\
\hline & Var & 7 & 20.0 \\
\hline \multirow[t]{2}{*}{ Sürekli kullanılan ilaç varlığ1 } & Yok & 31 & 88.6 \\
\hline & Var & 4 & 11.4 \\
\hline \multirow[t]{2}{*}{ Daha önce lokal anestezi altında ameliyat geçirme durumu } & Hayır & 27 & 77.1 \\
\hline & Evet & 8 & 22.9 \\
\hline \multirow[t]{2}{*}{ Daha önce diş ile ilgili cerrahi işlem geçirme durumu } & Hayır & 29 & 82.9 \\
\hline & Evet & 6 & 17.1 \\
\hline \multirow[t]{2}{*}{ Diş tedavisi sizin için korku verici midir? } & Hayır & 25 & 71.4 \\
\hline & Evet & 10 & 28.6 \\
\hline Toplam & & 35 & 100 \\
\hline
\end{tabular}


Corah'ın dental anksiyete skalasına göre araştırmaya katılan hastaların 42.9\%'unda $(\mathrm{n}=15)$ anksiyete yok iken, 57.1\%'inde anksiyete varlığ1 $(\mathrm{n}=20)$ belirlenmiştir. Çalışmaya katılan hastaların gevşeme egzersizi öncesi ve sonrası yaşam bulguları ve ağız açıklığı ortalamaları karşılaştırmalı olarak Tablo 2'de verilmiştir. Araştırma kapsamına alınan hastaların gevşeme egzersizi öncesi sistolik kan basıncı (SKB) ortalamas1 $132.0 \pm 21.94$, uygulama sonrasi SKB ortalaması $129.14 \pm 20.49 \mathrm{mmHg}$ olarak belirlenmiş ve aradaki fark istatistiksel olarak anlamlı bulunmuştur $(\mathrm{p}<0.01)$. Hastaların gevşeme egzersizi öncesi diyastolik kan basınc1 (DKB) ortalamas1 83.14 $\pm 13.45 \mathrm{mmHg}$, uygulama sonras1 DKB ortalamas1 $81.26 \pm 11.33 \mathrm{mmHg}$ olarak belirlenmiş ve aradaki fark istatistiksel olarak anlamı olarak bulunmamıştır ( $p>0,05)$. Gevşeme egzersizi öncesi nabız hız ortalamas1 $79.94 \pm 4.16 \mathrm{dk}$ iken uygulama sonras1 nabiz hiz ortalamas1 ise $80.17 \pm 3.81 \mathrm{dk}$ olarak belirlenmiş ve aradaki fark istatistiksel olarak anlamlı bulunmamıştır $(\mathrm{p}>0,05)$. Solunum hızı ortalaması ise egzersiz öncesi 15,48 \pm 1,59 dk, sonras1 solunum hız1 ortalamas1 15,31 $\pm 1,30 \mathrm{dk}$ olarak belirlenmiş ve aradaki fark istatistiksel olarak anlamlı olmadığı tespit edilmiştir ( $p>0,05)$. Hastaların ağız açıklığı ortalaması ise egzersiz öncesi $44.03 \pm 4.76 \mathrm{~mm}$, uygulama sonras 1 ağız açıklı̆g 1 ortalamas $45.03 \pm 5.75 \mathrm{~mm}$ olarak belirlenmiș ve aradaki fark istatistiksel olarak anlamlı bulunmuştur $(p<0,01)$.

Tablo 2. Hastaların gevşeme egzersizi öncesi ve sonrası yaşam bulguları ortalamalarının karşılaştırılması

\begin{tabular}{|l|c|c|c|}
\hline Yaşam Bulguları & $\begin{array}{c}\text { Gevşeme Egzersizi } \\
\text { Öncesi }\end{array}$ & $\begin{array}{c}\text { Gevşeme Egzersizi } \\
\text { Sonras1 }\end{array}$ & P value \\
\hline Sistolik Kan Basınc1 (mmHg) & $132.0 \pm 21.94$ & $129.14 \pm 20.49$ & $.023^{* *}$ \\
\hline Diastolik Kan Basıncı (mmHg) & $83.14 \pm 13.45$ & $81.26 \pm 11.33$ & .130 \\
\hline Nabız (dk) & $79.94 \pm 4.16$ & $80.17 \pm 3.81$ & .160 \\
\hline Solunum (dk) & $15.31 \pm 1.36$ & $15.20 \pm 1.11$ & .324 \\
\hline Ağız Açıklı̆1 & $44.02 \pm 4.12$ & $45.02 \pm 3.99$ & $.000^{* * *}$ \\
\hline
\end{tabular}

$\mathrm{n}=35,{ }^{* * *} \mathrm{p}<0.001,{ }^{* *} \mathrm{p}<0.05$ anlamlı olarak kabul edildi.

\section{TARTIŞMA}

$\mathrm{Bu}$ çalışma, periodontal cerrahi uygulamaları için gelen hastaların dental anksiyete düzeyleri ve cerrahi öncesi uygulanan gevşeme egzersizlerinin sistolik kan basinc1, diastolik kan basınc1, nabız, solunum ve ağız açıklığ1 üzerine etkisini incelemek amaciyla planlanmıştır.

Dental anksiyete, toplumda yaygındır ve genel popülasyonun yarısından fazlasını etkileyebilir. Yetişkin, çocuk ve ergenlerin diş tedavileri için önemli bir konudur. Dental anksiyete, yetişkinlerin \%1020 'sini ve çocukların ve ergenlerin \%43'ünü etkiler ${ }^{20,21}$.

Diş hekimliğinde cerrahi uygulamalar oldukça endişe vericidir. Periodontal cerrahi işlemler, iyileşme süresi kısa ve hayati riskin düşük olduğu lokal cerrahi prosedürler olmasına rağmen fiziksel ve psikolojik nedenler ile preoperatif anksiyeteyi arttırmaktadır. Yapılan bir araştırmada periodontal tedavi alan hastalar cerrahi tedavi öncesi ağrı yaşayacakları nedeni ile yüksek anksiyete düzeyine sahip oldukları bildirilmiştir ${ }^{22}$.

Corah Dental Anksiyete Ölçeği (CDAS), yetişkinlerde dental anksiyete düzeylerini belirlemek için kullanılan dental anksiyete ölçeklerinden biridir. Corah Dental Anksiyete Ölçeği, uygulama kolaylığı ve yeterli psikometrik özelliklere sahip bir değerlendirme ölçeğidir ${ }^{23}$. Çalışma sonuçlarımızda hastaların $71.4 \%$ 'ü diş tedavilerinin korku verici olmadığını ifade etmelerine rağmen 57.1\%'inde dental anksiyete varlığ1 tespit edilmiştir. Dental cerrahilerin lokal cerrahi ile yapılması ve cerrahi sırasında bilincin açık olması anksiyeteni artmasını sağlayan başlica sebeplerdir. Muğlalı ve arkadaşlarının 2008'te yaptığı çalışmaya göre ağız cerrahisi işlemi uygulanacak hastaların sadece \%5'inin hiçbir kayg1 hissetmediği bildirilmiştir ${ }^{24}$.

Dental anksiyetenin azaltılmas1/giderilmesinde farmakolojik, farmakolojik olmayan veya her ikisinin beraber kullanıldığı teknikler kullanılmaktadır. Farmakolojik müdahaleler arasında benzodiazepinler, azot oksit, genel anestezi ve diğer maddeler (kloralhidrat ve hidroksi) bulunur. Diş hekimliğindeki bilinçli sedasyon uygulaması ise diş tedavisi maliyetinin yanı sıra çeşitli istenmeyen etki ve riskleri arttırmışır. Soluma, sedasyon (azot oksit), bilinçli intravenöz sedasyon ve oral sedasyon içerir ve bunların maliyeti yüksektir. Tedaviye uyum için profesyonel diş bakımının maliyeti çok önemlidir. Farmakolojik tedaviler bulant1, kusma, solunum 
depresyonu, kalp atım hızı ve kan basıncını azaltması gibi dezavantajlara sahiptir. Böylece, sedatif etkili alternatif tedavilerin önemi $\operatorname{artar}^{25}$. Farmakolojik olmayan müdahaleler arasında masaj, refleksoloji, gevşeme egzersizleri ve hayal kurma, müzik terapi, resim yapma, yoga, akapunktur, akupresür, hasta eğitimi hipnoz, reiki, terapötik dokunma sanal gerçeklik, görsel-işitsel dikkat dağıtma, müzikal dikkat dağıtma, güçlendirme, gösterme-söyleme vb. nonfarmakolojik yaklașımlardan bahsedilmektedir ${ }^{26,27}$. Progresif gevşeme egzersizleri nöromuskuler kas gerginliğini azaltmaya yönelik yöntemlerden biridir.

Karamustafaoğlu ve Yumrukçal'ın çalışmasında fobik uyaranla ilgili düşüncelerin olumlu hale getirilmesinde gevşeme egzersizlerinin uygulanabileceğinden bahsetmişlerdir ${ }^{28}$.

Dental anksiyete gibi olumsuz duygu ve psikosomatik hastalıklar nedeniyle kas gerginliği tetiklenmesi durumunda gevşeme egzersizlerinin otonom ve santral sinir sistemi uyarılmasını azalttı̆̆1 ve parasempatik sinir sisteminin aktivitesinin arttığ1 vurgulanmıştır ${ }^{29}$. Alan, jinekolojik kanserli hastalarda, yaptığ1 çalışmasında progresif kas gevşetme egzersizlerinin anksiyete seviyesinin düşürülmesinde etkili olduğunu ve güvenle kullanılması gerektiğini belirtmiştir ${ }^{30}$.

Dental anksiyete sırasında organizma stresle mücadele edebilmek için kan basıncı arttığı, kalp atışı ve soluk alıp verme hızlandığı ve kasların gerildiği bildirilmiştir. $^{3}$ Çalışma sonuçlarında hastaların gevşeme egzersizi öncesi ve sonrası sistolik ve diastolik kan basınç değerleri karşılaştırıldığında yüksek olan sistolik kan basıncı (SKB) önemli bir düşme kaydedilmiştir ve aradaki fark istatistiksel olarak ileri düzey anlamlı bulunmuştur. $(p<0.05$, Tablo 3). Bu sonuçlar periodontal cerrahi öncesi uygulanan gevşeme egzersizinin SKB'nın düşürülmesinde etkili olduğunu göstermektedir.

Dental anksiyete ile meydana gelen kas gerginliğinden ağız, yüz ve çene kasları da etkilenmektedir. Çalışma sonucunda gevşeme egzersizi uygulamasının ağız açıklığ1 ortalamasını anlamlı düzeyde arttırdığı bulunmuştur ( $<<0.001$, Tablo 3) Ağız açıklığının kısıtlılığ1 çene kaslarının strese verdiği cevaptan kaynaklanır. Ağı açılklı̆̆ı azalmış ve kısıtlanmış çenede ağız içi yapılacak operasyonu hem hasta hem hekim adına zorlaştıracaktır. Cerrahi öncesi uygulanacak olan müzik terapinin sedatif etkisi tedavi sırasında hasta ve cerrah için olumlu sonuçlar yaratacaktır. Ayrıca gevşeme egzersizlerinin myorelaksan özelliğinden dil de etkilenecek ve cerrahi çalışa kolaylığı sağlayacaktır.

Rainforth ve arkadaşlarının yaptıkları meta-analiz çalışmasının sonuçlarına göre, progresif gevşeme egzersizlerinin kas gevşemesi, artmış kan basıncının düşürülmesinde etkili olduğunu vurgulamıştır. Progresif gevşeme egzersizlerinin özellikle sistolik kan basıncinın düşürülmesinde etkili olduğunu bildiren çalışmalar da literatürde yer almaktadır ${ }^{32,33}$

Park ve ark. periodontal tedavi gereksinimi olan 68 birey üzerinde yapılan çalışmasında, hastaların dental anksiyete ile birlikte gelişen depresyon belirtilerinin, sistolik ve diyastolik kan basıncı, nabız hızı ve tükürük kortizol seviyelerinin önemli ölçüde azalmasında etkili olduğunu, progresif kas gevşetme terapisinin dental kaygıyı hafiflettiğini ve diş hekimliği alanında kullanılabileceğini belirmiştir ${ }^{34}$.

Sonuç olarak, periodontal cerrahi öncesi hastaların dental anksiyete düzeylerinin yüksek olduğu ve uygulanan progresif gevşeme egzersizlerinin cerrahi öncesinde anksiyeteye bağlı gelişen yükselmiş sistolik kan basıncının azaltılmasında ve çene kaslarının gevşetilerek ağızı açıklığını arttırılmasında uygulanabilecek ucuz, ağrisız, yan etkisiz nonfarmakolojik anksiyolitik etkili bir yöntemdir.

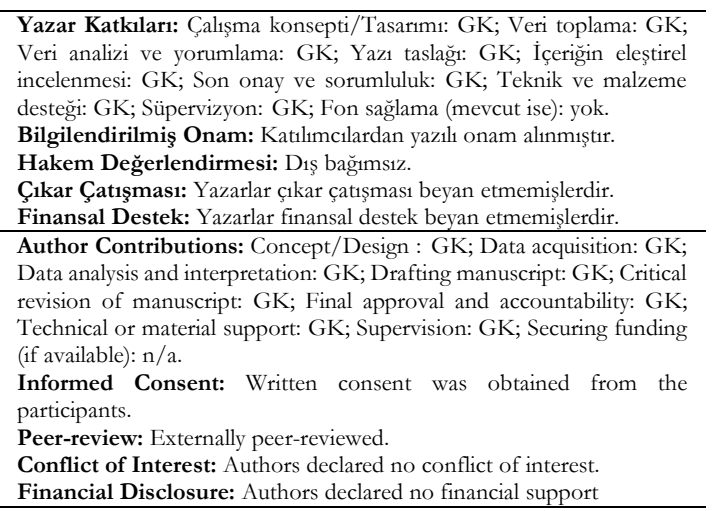

\section{KAYNAKLAR}

1. Suchetha A, Tanwar E, Darshan B, Bhat ASD. Postoperative complications after periodontal surgery. Anxiety. 2018;15:16

2. Cimilli C. Cerrahide anksiyete. Klinik Psikiyatri. 2001;4:182-6.

3. Cohen S, Fiske J, Newton J. Behavioural dentistry: The impact of dental anxiety on daily living. Br Dent J. 2000;189:385.

4. Boyar R, Cross M. Temperament and trait anxiety as predictors of child behavior prior to general 
anesthesia for dental surgery. Pediatr Dent. 1997;19:427-31

5. Şahin D. Periodontoloji kliniğine başvuran hastaların dental anksiyete düzeylerinin ve ağız sağlığı ile ilișkili yaşam kalitesinin belirlenmesi (Doktora Tezi). Ankara, Başkent Üniversitesi, 2014.

6. Şahin F, Biçer S, Yılmaz V, Çal TH. Kırşehir ağız ve diş sağllğ merkezine başvuran hastalarda dental anksiyete düzeyinin belirlenmesi. Bozok Tip Derg. 2013;1:26-33.

7. Babat S. Dental anksiyete, dental fobi ve hipnoz. Üsküdar Üni. Klinik Hipnoz ve Tamamlayıc Tip Derg. 2018;1:1-3.

8. Zabirunnisa M, Gadagi J S, Gadde P, Myla N, Koneru J, Thatimatla C. Dental patient anxiety: Possible deal with Lavender fragrance. J Res Phar Pract. 2014;3:100.

9. Doğaner YÇ, Aydoğan Ü, Yeşil HÜ, Sarı O, Koç B. Genç bireylerde dental anksiyete ve ilişkili faktörler. Gülhane Tip Derg. 2015;57:160-4.

10. Köroğlu A, Durkan R. Diş hekimliği uygulamalarında karşılaşılan dental anksiyete sendromunun etyolojisinin ve tedavi yöntemlerinin değerlendirilmesi. Atatürk Üni. Diş Hek. Fak. Derg. 2010;205-212.

11. Ergüven S, Kılınç Y, Delilbaşı E, Işık B. Bir diş hekimliği fakültesi ağız, diş ve çene cerrahisi kliniğine başvuran hastaların dental kayg1 düzeylerinin değerlendirilmesi. Acta Odontol Turc. 2014;32:7-11.

12. Öztürk M, Ay S. Bilinçli sedasyon. Cumhuriyet Üni. Diș Hek. Fak. Derg. 2000;3:121-6.

13. Özkalayc1 Ö. Pediatrik dental girişimlerde müzik dinletilmesinin sedasyon gereksinimi ve düzeyine etkisi (Uzmanlık Tezi). Ankara, Başkent Üniversitesi, 2015.

14. Demiralp M, Oflaz, F. Bilissel-davranisci terapi teknikleri ve psikiyatri hemsireligi uygulamasi. Anadolu Psikiyatri Derg. 2007;8:132.

15. Özveren H. Ağr1 kontrolünde farmakolojik olmayan yöntemler. Sağlık Bilimleri Fak. Hemşirelik Derg. 2011;83-92.

16. Uzun Ö. Ameliyat öncesi hasta eğitimi. Anadolu Hemşirelik ve Sağlık Bilimleri Derg. 2000;3:36-45.

17. Vurgeç B A, Alan S, Sürücü ŞG. Gevşeme tekniklerinin travaydaki ebelerin anksiyete düzeyleri üzerine etkisi. Mersin Üni. Tip Fak. Lokman Hekim Tip Tarihi ve Folklorik Tip Derg. 2018;8:282-91.

18. Corah NL. Development of a dental anxiety scale. J Dent Res.1968;47:154-7.

19. Seydaoğlu G, Doğan M C, Şükrü U, Yazgan İnanç B, Çelik M. Corah dental anksiyete skalasının Türkçe uyarlamasının geçerlilik-güvenilirliği ve dental anksiyete görülme sıklı̆ı. Ondokuz Mayıs Üniversitesi Diș Hekimliği Fakültesi Dergisi. 2006;7:7-14.

20. Oosterink FM, De Jongh A, Aartman IH. What are people afraid of during dental treatment? Anxietyprovoking capacity of 67 stimuli characteristic of the dental setting. Eur J Oral Sci. 2008;116:44-51.
21. Bradt J, Teague A. Music interventions for dental anxiety. Oral Dis. 2018;24:300-6.

22. Croog SH, Baume RM, Nalbandian J. Pre-surgery psychological characteristics, pain response and activities impairment in female patients with repeated periodontal surgery. J Psychosom Res. 1995;39:39-51.

23. Keleş S, Abacıgil F, Adana F, Yeşilfidan D, Okyay P. The association between dental anxiety and oral health related quality of life among individuals with mild intellectual disability. Meandros Med. and Dent. J. 2018;19:9.

24. Muglali M, Komerik N. Factors related to patients' anxiety before and after oral surgery. J Oral and Maxillofac Surg. 2008;66:870-7.

25. Wilson TD, McNeil DW, Kyle BN, Weaver BD, Graves RW. Effects of conscious sedation on patient recall of anxiety and pain after oral surgery. Oral Surg Oral Med Oral Pathol Oral Radiol. 2014;117:277-82.

26. Kocaman G, Benli NC. The effects of music therapy on vital signs and dental anxiety prior to dental surgery. Konuralp Tip Derg. 2019;11:308-13.

27. Rainforth MV, Schneider RH, Nidich SI, GaylordKing C, Salerno JW, Anderson JW Stress reduction programs in patients with elevated blood pressure: a systematic review and meta-analysis. Curr Hypertens Rep. 2007;9:520.

28. Karamustafalıoğlu O, Yumrukçal, H. Depresyon ve anksiyete bozuklukları. Şişli Etfal Hastanesi Tip Bülteni. 2011;45:65-74.

29. Cooke H. Progressive muscle relaxation. CAM Cancer Consortium. 2015;1-6.

30. Alan H. Jinekolojik kanser hastalarında kemoterapi tedavisi sürecinde uygulanan progresif kas gevşeme egzersizleri ve refleksolojinin ağrı, yorgunluk, anksiyete, depresyon ve yaşam kalitesi üzerine etkisi; randomize kontrol çalışması (Doktora Tezi). Ankara, Hacettepe Üniversitesi, 2015.

31. Rainforth MV, Schneider RH, Nidich SI, GaylordKing C, Salerno JW, Anderson JW. Stress reduction programs in patients with elevated blood pressure: a systematic review and meta-analysis. Curr Hypertens Rep._2007;9:520.

32. Schneider RH, Staggers F, Alexander CN, Sheppard W, Rainforth M, Kondwani K, King CG. A randomized controlled trial of stress reduction for hypertension in older African Americans. Hypertension. 1995;26:820-827.27.

33. Schneider RH, Alexander CN, Staggers F, OrmeJohnson DW, Rainforth M, Salerno JW, ..Nidich SI. A randomized controlled trial of stress reduction in African Americans treated for hypertension for over one year. Am Journal of Hypertens. 2005;18:88-98.

34. Park ES, Yim HW, Lee KS. Progressive muscle relaxation therapy to relieve dental anxiety: a randomized controlled trial. Eur J Oral Sci. 2019;127:45-51. 